\title{
Assessment of maternal self-efficacy in breastfeeding in the immediate puerperium
}

\author{
Avaliação da autoeficácia materna em amamentar no puerpério imediato
}

Bárbara Brandão Lopes ${ }^{1}$, Anne Fayma Chaves Lopes ${ }^{1}$, Dharlene Giffoni Soares ${ }^{2}$, Hilana Dayana Dodou ${ }^{1}$, Régia Christina Moura Barbosa Castro ${ }^{1}$, Mônica Oliveira Batista Oriá ${ }^{1}$

Objective: to evaluate the maternal self-efficacy in breastfeeding in the immediate puerperium. Methods: this is a cross-sectional study involving 132 puerperae. A form with sociodemographic and obstetrical data and the Breastfeeding Self-Efficacy Scale - Short Form was applied in the rooming-in maternity ward. Results: the majority of the interviewed women presented high self-efficacy $(90.9 \%)$ and presented medium (9.1\%) selfefficacy in breastfeeding. There was no association between Breastfeeding Self-Efficacy Scale-Short Form scores and sociodemographic and obstetric variables. Conclusion: women presented high self-efficacy in breastfeeding, which points to a favorable expectation towards breastfeeding, and nurse professional are required to provide more effective assistance in breastfeeding support.

Descriptors: Breast Feeding; Self Efficacy, Nursing, Postpartum Period.

Objetivo: avaliar a autoeficácia materna em amamentar no puerpério imediato. Métodos: estudo transversal que envolveu 132 puérperas. No alojamento conjunto, foi aplicado formulário com dados sociodemográficos e obstétricos e a Breastfeeding Self-Efficacy Scale - Short Form. Resultados: a maioria das mulheres entrevistadas apresentou elevada $(90,9 \%)$ e média $(9,1 \%)$ autoeficácia em amamentar. Não houve associação entre os escores da Breastfeeding Self-Efficacy Scale - Short Form e as variáveis sociodemográficas e obstétricas. Conclusão: as mulheres apresentaram elevada autoeficácia em amamentar, o que remete à expectativa favorável ao aleitamento materno, sendo necessário acompanhamento do profissional enfermeiro para garantir assistência mais efetiva no apoio à amamentação.

Descritores: Aleitamento Materno; Autoeficácia; Enfermagem; Período Pós-Parto.

\footnotetext{
* Extracted from the end-of-course work entitled "Avaliação da autoeficácia materna em amamentar através da Breastfeeding Self-Efficacy Scale - Short Form", Universidade Federal do Ceará, 2016.

${ }^{1}$ Universidade Federal do Ceará. Fortaleza, CE, Brazil.

${ }^{2}$ Universidade de Fortaleza. Fortaleza, CE, Brazil.

Corresponding author: Bárbara Brandão Lopes

Rua Benjamim Constant, 416 - Pici. CEP: 60440-536. Fortaleza, CE, Brazil. E-mail: barbara_brandao92@hotmail.com
} 


\section{Introduction}

The practice of breastfeeding goes beyond the child's nutrition. It can also be considered a natural way of creating a bond, and showing affection and protection between the mother-child binomial. Moreover, breastfeeding is considered an economical and effective strategy to reduce infant morbidity and mortality ${ }^{(1)}$. In nursing care, several interventions have been proposed in order to promote this action and prevent early weaning. However, monitoring and continuity of breastfeeding is still a challenging goal to be achieved.

Although government health authorities have reinforced the importance of exclusive breastfeeding in the case of children up to six months of age, the prevalence rate of this type of breastfeeding in Brazilian children under 6 months of age is only $41.0 \%$. Thus, more efforts are necessary so as the country reaches satisfactory rates ${ }^{(2-3)}$.

There are many factors that interfere with lactation. They include non-child-friendly hospitals, schooling ( $\leq 8$ years of schooling), lack of knowledge of the mothers about the affective bond in the mother-child binomial, belief in insufficient milk production, several postpartum breast complications ${ }^{(4-5)}$. It is necessary to modify the conditioning factors on the part of health professionals. Self-efficacy in breastfeeding emerges in this perspective, and consists in the self-confidence of women regarding their knowledge and skills to successfully breastfeed their child, a fundamental aspect for the beginning, duration and exclusivity of this process ${ }^{(6-7)}$.

Self-efficacy is important because it is a concept of health promotion capable of revealing the expectation and confidence of women to breastfeed their children, as well as an influent factor on other behaviors that will impact the children' health indicators ${ }^{(7)}$. In this sense, for nurses to be able to effectively act in this context, it is essential that they have scientific knowledge about the subject and about the determining and conditioning factors, given that nursing care and nursing guidance can directly influence the breastfeeding process. The objective of the present study was to evaluate maternal self-efficacy in breastfeeding in the immediate puerperium.

\section{Methods}

This is a cross-sectional study developed with 132 women who were in the immediate postpartum, hospitalized in the rooming-in maternity ward of a reference maternity hospital in Fortaleza, CE, Brazil.

Sample selection obeyed the following inclusion criteria: puerperal women in the immediate puerperium (between the first and tenth day postpartum), with at least six hours postpartum, full term gestation, with newborns hospitalized in rooming-in wards and being breastfed. The exclusion criteria adopted were: puerperal women who had been contraindicated to breastfeeding, whose children were born with disabilities that impeded breastfeeding, women with mental restrictions that made it impossible to understand the scale/instrument, and women who had had delivery and postpartum complications.

Data collection occurred between May and June 2015. The puerperal women were approached in the rooming-in wards where they were hospitalized and the objectives and benefits of the research were explained. Then, the researchers collected the data through a self-filled form addressing characteristics of sociodemographic (age, race, schooling, marital status, number of residents at home, use of tobacco and alcohol), economic (family income and paid work activity) and obstetric nature (gestational age, prenatal care, including number of consultations, pregnancy complications, type of delivery, previous children, prior breastfeeding practice, and whether the baby had been breastfed immediately after delivery).

In addition to this form, the Breastfeeding Self-Efficacy Scale - Short Form (BSES-SF) was applied to evaluate the self-efficacy of the puerperal women ${ }^{(8)}$. This form consists of a Likert-type scale composed of 
14 items distributed in two domains (intrapersonal and technical domains). Each item is scored (from $1=$ totally disagree to $5=$ totally agree), so that the total score ranges from 14-70 points, which are classified as follows: low self-efficacy: 14 to 32 points; medium self-efficacy: 33 to 51 points; high self-efficacy: 52 to 70 points.

Data was compiled, stored in a database in the Microsoft ${ }^{\circledR}$ Office Excel program of Windows Starter 7 (Microsoft Corporation version 2003-2007), and then analyzed in the Epi Info software version 3.5.3. After typing and checking the consistency of the data, dispersion measures such as absolute and relative frequency and standard deviations (SD) were calculated, as well as measures of central tendency, and then the descriptive analysis of the variables was performed. The Pearson's Chi-square and Fisher's exact tests were used to test the association between sociodemographic and obstetric variables.

The study complied with the formal requirements contained in the national and international regulatory standards for research involving human beings.

\section{Results}

The age of the participants ranged from 15 to 35 years, with a mean of 23 years (SD \pm 4.8 ). Women who were married or common-law married (102; $77.3 \%$ ), with high schooling ( $\geq 9$ years of schooling) (92; 69.7\%), who practiced activities outside the home environment $(71 ; 53.8 \%)$, and who lived with less than one minimum wage ( $\mathrm{R} \$ 788.00$, at the time of the study) $(85 ; 64.4 \%)$ predominated.

Regarding the obstetric history, most of the women had not planned the pregnancy (82; 62.1\%), but had performed more than six prenatal visits (98; $74.2 \%$ ). For most of the women this was the first child (74; 56.1\%), they had not previously breastfed (80; $60.3 \%)$, they had had cesarean delivery $(81 ; 61.4 \%)$ and had not breastfed immediately after delivery (67; 50.8\%). As for self-efficacy in breastfeeding, 120 $(90.9 \%)$ women were classified as presenting high self-efficacy and the others, medium self-efficacy. Thus most of the breastfeeding women felt confident in the act of breastfeeding. None of them had low efficacy in breastfeeding.

Tables 1 and 2 present the association between maternal self-efficacy in breastfeeding and socioeconomic and obstetric data.

Table 1 - Association between the types of self-efficacy (BSES-SF) and sociodemographic data

\begin{tabular}{lcc}
\hline Variables & $\begin{array}{c}\text { Medium Self- High self- } \\
\text { efficacy }\end{array}$ & efficacy \\
\cline { 2 - 3 } & p (\%) & n (\%)
\end{tabular}

Age (years)

\begin{tabular}{|c|c|c|c|}
\hline$<15$ & $3(25.0)$ & $18(15.0)$ & \\
\hline $15-35$ & $9(75.0)$ & $88(73.3)$ & $0.351^{* *}$ \\
\hline$>35$ & - & $14(11.7)$ & \\
\hline
\end{tabular}

Marital status

With partner $8(66.7) \quad 94(78.3) 0.276^{* * *}$

Without partner

$4(33.3) \quad 26(21.7)$

Schooling (years)

\begin{tabular}{|c|c|c|c|}
\hline $1-4$ & $1(8.3)$ & $3(2.5)$ & \\
\hline $5-8$ & $6(50.0)$ & $30(25.0)$ & $0.073^{* *}$ \\
\hline$\geq 9$ & $5(41.7)$ & $87(72.5)$ & \\
\hline
\end{tabular}

Occupation

Work outside the home $\quad 6(50.0) \quad 65(54.2) 0.508^{* * *}$ Housewives $\quad 6(50.0) \quad 55(45.8)$

Family income (minimum wages)*

$\begin{array}{lll}\leq 1 & 9(75.0) & 76(63.3) 0.320^{* * *} \\ >1 & 3(25.0) & 44(36.7)\end{array}$

*Minimum wage at the time of data collection (R\$ 788.00); **Chi-square test; ***Fisher's exact test 
Table 2 - Association between the types of self-efficacy (BSES-SF) and obstetric data

\begin{tabular}{lccc}
\hline \multirow{2}{*}{ Variables } & $\begin{array}{c}\text { Medium } \\
\text { Self-efficacy }\end{array}$ & $\begin{array}{c}\text { High self- } \\
\text { efficacy }\end{array}$ & \multirow{2}{*}{$\mathbf{p}^{*}$} \\
\cline { 2 - 3 } & $\mathbf{n}(\%)$ & $\mathbf{n}(\%)$ & \\
\hline Previous breastfeeding practice & & & \\
Yes & $4(33.3)$ & $48(40.0)$ & 0.451 \\
No & $8(66.7)$ & $72(60.0)$ & \\
Prenatal consultations & & & \\
$<6$ & $2(16.7)$ & $32(26.7)$ & 0.357 \\
$\geq 6$ & $10(83.3)$ & $88(73.3)$ & \\
Current delivery type & & & \\
Vaginal & $4(33.3)$ & $47(39.2)$ & 0.474 \\
Cesarean & $8(66.7)$ & $73(60.8)$ & \\
Breastfed in the first hour after delivery & & \\
Yes & $6(50.0)$ & $59(49.2)$ & 0.596 \\
No & $6(50.0)$ & $61(50.8)$ & \\
*Fisher's exact test & & &
\end{tabular}

There was no statistical significance in any of the associations in the correlations between BSES-SF scores and sociodemographic and obstetric variables.

\section{Discussion}

One limitation of this study was the assessment of maternal self-efficacy at single moment. Longitudinal studies are recommended seeking to compare this variable in different postpartum periods.

It was evidenced in this study that the majority of the women presented high self-efficacy in breastfeeding (90.9\%). This finding is positive considering that the national and international literature point to this criterion as a protective factor for exclusive breastfeeding ${ }^{(4,9)}$.

This result is similar to a research carried out in the northeastern and southeastern regions of Brazil where mothers with medium and high self-efficacy in breastfeeding were also found ${ }^{(10-11)}$. This finding indicates that women living in different regions of Brazil feel confident about breastfeeding; thus, if the prevalence of breastfeeding or exclusive breastfeeding has not reached the international recommended levels, this may mean that factors other than self-efficacy are interfering with the women's decision to breastfeed. Thus, it is imperative that in addition to maintaining this confidence, nurses seek to identify which technical or intrapersonal factors have been causing early weaning.

It was also found that age did not have a significant influence. However, national and international surveys involving adolescents point to lower rates of onset and duration of breastfeeding in the first six months of the baby's life, and it is important to note that the age is a factor that may interfere with the lactation process $^{(12-13)}$.

Regarding marital status, a study shows that living with a partner influences maternal confidence because the participation of the partner in supporting these women during the pregnancy-puerperal cycle favors the duration and maintenance of breastfee$\operatorname{ding}^{(14)}$.

Schooling is another important variable in the context of breastfeeding. This aspect is considered a protective factor ${ }^{(14)}$. In disagreement with the findings of the present article, a study carried out with 79 mothers in a public maternity hospital in Fortaleza-CE, Brazil, showed a significant association of maternal self-efficacy in breastfeeding with the educational level $(\mathrm{p}=0.032)^{(15)}$.

There was a predominance of women living with a family income of up to one minimum wage $(64.4 \%)$ in this study. Although the literature indicates that low family income is an aspect that favors early weaning ${ }^{(16-17)}$, recent epidemiological and biological findings from the last decade have shown that poor women breastfeed longer than the richest women in low- and medium-income countries ${ }^{(18)}$.

Regarding occupation and confidence in breastfeeding, no significant association was observed. However, maternal work is also a condition that favors the non-adherence to exclusive breastfeeding because women often work to help with household expenses and, in other cases, they even assume the role of heads of household. Thus, due to financial necessity, they are 
led to perform extra-home labor activities and abandon exclusive breastfeeding of their children ${ }^{(19)}$.

The Brazilian literature emphasizes that women who perform more than six prenatal visits have higher rates of self-efficacy in breastfeeding ${ }^{(20)}$. This datum shows that is necessary to actively seek pregnant women, as well as encourage nurses to perform this care, since the guidelines passed during the nursing consultations have an impact on the decision of women to breastfeed.

Regarding the type of delivery, an integrative review involving the Medical Literature Analysis and Retrieval System Online and the Latin American and Caribbean Health Sciences Literature databases showed that women who had vaginal delivery had higher levels of confidence in breastfeeding, being this a positive aspect for breastfeeding $(\mathrm{p}=0.03)^{(17,20)}$.

Although personal experience is one of the pillars of the breastfeeding process, there was no significant relationship between the previous practice of breastfeeding and self-efficacy in breastfeeding. It is pertinent, however, that mothers with breastfeeding experience had been reported to have higher levels of confidence in this process $(\mathrm{p}=0.034)^{(17)}$.

On the other hand, the literature highlights that among the factors associated with the abandonment of breastfeeding during the first six months of life of the child is the lack of experience with breastfeeding, in fact a variable that leads to a high risk for early weaning ${ }^{(4,19)}$. Thus, this aspect should be considered by health professionals in activities developed in primary care units through shared dialogue in which patients with positive breastfeeding experience share their knowledge on practices with women who have never had this experience or who had a previous negative experience.

Another relevant aspect regarding the theme discussed is the time the child is taken to the breast to be breastfed after childbirth. In this article, this variable was not associated with the self-efficacy of this process. However, a longitudinal research showed that the best confidence levels of pre-natal and pos- tpartum women were manifested by those who breastfed their babies in the first hour of life ${ }^{(20)}$.

Another study involving 322 postpartum women found that mothers who breastfed their children one hour after delivery had higher self-efficacy sco$\operatorname{res}^{(9)}$. Thus, we can see how important this aspect is to the success of breastfeeding. It is fundamental that health professionals promote strategies in obstetrics units.

Therefore, the importance of health professionals, especially nurses, in the care during the immediate puerperium, in the rooming-in wards, and in the follow-up of breastfeeding in childcare consultations is noticeable. To this end, they must use targeted strategies of health education as a tool in order to foster maternal confidence, as well as to focus on aspects that may interfere in the women's self-confidence to breastfeed.

\section{Conclusion}

Based on the application of the BSES-SF, the women in the present study showed a high self-efficacy in breastfeeding, which points a favorable expectation of breastfeeding, and nurses are required to provide more effective assistance and support to the practice of breastfeeding. However, high confidence rates do not indicate the absence of difficulties, and assistance during this period is necessary, since this aspect is susceptible to change.

\section{Collaborations}

Lopes $\mathrm{BB}$ and Lopes $\mathrm{AFC}$ contributed to the conception, analysis, interpretation of data, writing of the article, critical review of the content, and final approval of the version to be published. Soares DG and Dodou HD contributed to the designing of the work, collection and interpretation of the data. Castro RCMB and Oriá MOB contributed to the writing of the article and final approval of the version to be published. 


\section{References}

1. Ministério da Saúde (BR). Saúde da criança - nutrição infantil: aleitamento materno e alimentação complementar. Brasília: Ministério da Saúde; 2015.

2. Passanha A, Benício MHDA, Venâncio SI, Reis MCG. Implementation of the Brazilian breastfeeding network and prevalence of exclusive breastfeeding. Rev Saúde Pública. 2013; 47(6):1141-8. doi: http://dx.doi.org/10.1590/ S0034-8910.2013047004807

3. Kaufmann CC, Albernaz EP, Silveira RB, Silva MB, Mascarenhas MLW. Alimentação nos primeiros três meses de vida dos bebês de uma coorte na cidade de Pelotas, Rio Grande do Sul. Rev Paul Pediatr. 2012; 30(2):157-65. doi: http://dx.doi. org/10.1590/S0103-05822012000200002

4. Margotti E, Epifanio M. Exclusive maternal breastfeeding and the Breastfeeding Self-efficacy Scale. Rev Rene. 2014; 15(5):771-9. doi: http://dx.doi. org/10.15253/2175-6783.2014000500006

5. Amaral LJX, Sales SS, Carvalho DPSRP, Cruz GKP, Azevedo IC, Ferreira Júnior MA. Factors that influence the interruption of exclusive breastfeeding in nursing mothers. Rev Gaúcha Enferm. 2015; 36(esp):127-34. doi: http://dx.doi. org/10.1590/1983-1447.2015.esp.56676

6. Otsuka K, Taguri M, Dennis CL, Wakutani K, Awano M, Yamaguchi T, et al. Effectiveness of a breastfeeding self-efficacy intervention: do hospital practices make a difference? Matern Child Health J. 2014; 18(1):296-306. doi: http:// dx.doi.org/10.1007/s10995-013-1265-2

7. Dodt RCM, Ximenes LB, Oriá MOB. Validation of a flip chart for promoting breastfeeding. Acta Paul Enferm. 2012; 25(2):225-30. doi: http://dx.doi. org/10.1590/S0103-21002012000200011

8. Dodt RCM, Ximenes LB, Almeida PC, Oriá MOB, Dennis CL. Psychometric assessment of the short form version of the breastfeeding self-efficacy scale in a Brazilian sample. J Nurs Educ Pract. 2012; 2(3):66-73. doi: http://dx.doi.org/10.5430/jnep. v2n3p66
9. Rodrigues AP, Padoin SMM, Guido LA, Lopes LFD. Pre-natal and puerperium factors that interfere on self-efficacy in breastfeeding. Esc Anna Nery. 2014; 18(2):257-61. doi: http://dx.doi. org/10.5935/1414-8145.20140037

10. Chaves AFL, Lima GP, Melo GM, Rocha RS, Vasconcelos HCA, Oriá MOB. Flipchart application for promoting maternal self-efficacy in breastfeeding. Rev Rene. 2015; 16(3):407-14. doi: http://dx.doi. org/10.15253/2175-6783.2015000300014

11. Souza EFC, Fernandes RAQ. Breastfeeding selfefficacy: a cohort study. Acta Paul Enferm. 2014; 27(5):465-70. doi: http://dx.doi. org/10.1590/1982-0194201400076

12. Kingston D, Heaman M, Fell D, Chalmers B. Comparison of adolescent, young adult, and adult women's maternity experiences and practices. Pediatrics. 2012; 129(5):1228-37. doi: http:// dx.doi.org/10.1542/peds.2011-1447

13. Gusmão AM, Béria JU, Gigante LP, Leal AF, Schermann LB. Prevalência de aleitamento materno exclusivo e fatores associados: estudo transversal com mães adolescentes de 14 a 16 anos em Porto Alegre, RS, Brasil. Ciênc Saúde Coletiva. 2013; 18(11):3357-68. doi: http://dx.doi. org/10.1590/S1413-81232013001100025

14. Uchôa JL, Gomes ALA, Joventino ES, Oriá MOB, Ximenes LB, Almeida PC. Antecedentes sociodemográficos e obstétricos na autoeficácia materna em amamentar: estudo em painel. Online Braz J Nurs. 2014; 13(4):645-55. doi: http:// dx.doi.org/10.5935/1676-4285.20144708

15. Santos LMD, Rocha RS, Chaves AFL, Dodou HD, Castelo ARP, Feitoza SR, et al. Application and Validation of Breastfeeding Self-Efficacy Scale, Short Form (BSES-SF) in Adolescent Mothers. Int Arch Med Sec Nurs. 2016; 9(207):1-9. doi: http:// dx.doi.org/10.3823/2078

16. Dodt RCM, Ferreira AMV, Nascimento LA, Macêdo AC, Joventino ES, Ximenes LB. Influence of health education strategy mediated by a self-efficacy breastfeeding serial album. Texto Contexto Enferm. 2013; 22(3):610-8. doi: http://dx.doi. org/10.1590/S0104-07072013000300006 
17. Rodrigues AP, Padoin SMM, de Paula CC, Guido LA. Factors those influence in self-efficacy of breastfeeding: Integrative review. Rev Enferm UFPE online [Internet]. 2013 [cited 2017 Oct 13]; 7(esp):4144-52. doi: Available from: http://www. revista.ufpe.br/revistaenfermagem/index.php/ revista/article/viewArticle/4031

18. Victora CG, Barros AJD, França GVA, Bahl R, Rollins NC, Horton S, et al. Breastfeeding in the 21st century: epidemiology, mechanisms, and lifelong effect. Lancet. 2016; 387(10017):47590. doi: http://dx.doi.org/10.1016/S01406736(15)01024-7
19. Salustiano LPQ Diniz ALD, Abadallaha VOS, Pinto RMC. Fatores associados à duração do aleitamento materno em crianças menores de seis meses. Rev Bras Ginecol Obstet. 2012; 34(1):2833. doi: http://dx.doi.org/10.1590/S010072032012000100006

20. Uchôa JL, Rodrigues AP, Joventino ES, Almeida $\mathrm{PC}$, Oriá MOB, Ximenes LB. The self-efficacy in breastfeeding of women in the prenatal and postpartum: longitudinal study. Rev Enferm UFSM. 2016; 6(1):10-20. doi: http://dx.doi. org/10.5902/2179769217687 